\title{
Laser Scanner Terrestre: teoria, aplicações e prática
}

\author{
Terrestrial laser scanner: theory, applications and practice.
}

\author{
Rodrigo da Silva Ferraz ${ }^{1}$ \\ Sérgio Florêncio de Souza ${ }^{1}$ \\ Mário Luiz Lopes Reis ${ }^{2}$
}

\begin{abstract}
${ }^{1}$ Centro Estadual de Pesquisas em Sensoriamento Remoto e Meteorologia (CEPSRM) - Universidade Federal do Rio Grande do Sul - UFRGS - Avenida Bento Gonçalves 9500 - Campus do Vale, Bairro Agronomia, CEP: 91501-970, Porto Alegre - RS.

${ }^{2}$ Laboratório de Pesquisas em Fotogrametria - Departamento de Geodésia - Instituto de Geociências - Universidade Federal do Rio Grande do Sul - UFRGS - Avenida Bento Gonçalves 9500 - Campus do Vale, Bairro Agronomia, CEP: 91501-970, Porto Alegre-RS.
\end{abstract}

rferraz1980@gmail.com, sergio.florencio@ufrgs.br, mario.reiss@ufrgs.br

Recebido em 30/04/2016 - Aceito em 13/06/2016

Received on 30/04/2016 - Accepted on 13/06/2016

\begin{abstract}
RESUMO - A utilização de um Sistema de Varredura Laser Terrestre (SVLT) possui inúmeras aplicações nas diversas áreas envolvidas em levantamentos tridimensionais. Possui ampla utilização na mineração para cálculos de volumes, registro de monumentos históricos, geração de modelos digitais de superfície (MDS), modelos digitais de terreno (MDT) e aplicações na arquitetura. O produto principal gerado por um SVLT é uma nuvem de pontos com coordenadas tridimensionais referenciadas ao centro de fase do sensor, que, após processos matemáticos denominado de registro, gera uma nuvem de pontos georreferenciada. Além das coordenadas tridimensionais o SVLT fornece também a intensidade de retorno do sinal, que é a energia captada pelo sensor em função da resposta espectral emitida pelo alvo. Dependendo das características do sistema, à nuvem de pontos pode-se adicionar cores a partir de fotografias das cenas que são obtidas durante as varreduras. As nuvens de pontos modelam diferentes tipos de feições existentes no terreno como vegetação, edificações, rochas, estruturas, etc. Assim, o objetivo desse trabalho é realizar uma abordagem dos principais conceitos envolvidos em relação a um SVLT, classificação de dados oriundos das nuvens de pontos e suas aplicações na geração de MDT.
\end{abstract}

Palavras-chave: Sistema de Varredura Laser Terrestre, Modelo Digital de Terreno, intensidade de retorno de sinal.

ABSTRACT - Terrestrial Laser Scanner System (SVLT) systems have several applications in three-dimensional surveys. It has widespread use in mining for calculating volumes, register of cultural heritage, generation of digital surface models (DSM), digital terrain models (DTM), and architectural applications. The main product generated by the SVLT systems is a cloud points with three-dimensional coordinates referenced to the phase center of the TLS. This cloud points can also be mathematical processed, generate a cloud points georeferenced. In addition to the three-dimensional coordinates, the SVLT also provide the laser return signal intensity that is the energy acquired by the sensor depending on the spectral response emitted by the target. Depends on the characteristics of the SVLT, the point clouds can have colors from scenes through photographs acquired by integration of the system with cameras. The point clouds model different types of features on the ground such as: vegetation, buildings, rocks, structures, etc. The purpose of this paper is to approach the main concepts involved in relation to an SVLT, data classification derived from point clouds and its applications for generate DTMs.

Keywords: System Scanning Laser Terrestrial, Digital Terrain Model, intensity return signal.

\section{INTRODUÇÃO}

Os sistemas LIDAR (Light Detection and Ranging Obtenção de medidas de distância através da luz) são uma tecnologia que envolvem sensores ativos que podem operar tanto na faixa do espectro eletromagnético do visível até o infravermelho médio. Para fins cartográficos a tecnologia LIDAR pode ser utilizada a partir de plataformas terrestres e aerotransportadas. O presente estudo visa elaborar uma abordagem conceitual em relação aos princípios de funcionamento de SVLT. Também serão abordados alguns conceitos envolvendo Modelos Digitais de Terreno (MDT) gerados a partir de Sistemas de Varredura Aerotransportados (SVAT), assim como uma análise de controle de qualidade posicional de dados oriundos de dois diferentes SVLT. No presente trabalho também serão 
abordados pequenos tópicos envolvendo os sistemas aerotransportados bem como uma pequena comparação desse tipo de aquisição com as plataformas terrestres.

Um SVLT é um aparelho que usa um laser para medir as coordenadas tridimensionais de uma dada região ou a superfície de um objeto automaticamente. Os dados coletados são denominados de "nuvens de pontos" que fornecem os valores de $\mathrm{X}, \mathrm{Y}, \mathrm{Z}$ dos pontos medidos na superfície escaneada, bem como um valor de intensidade de retorno do sinal (BARBER, 2003).

Segundo Wutke (2006), existem dois tipos de sistemas de varredura laser: os sistemas estáticos, em que o equipamento fica estacionado em um determinado local para coleta de dados, e os sistemas dinâmicos, em que o equipamento fica em movimento durante a aquisição dados. Os sistemas estáticos são aqueles, cuja aquisição das varreduras é feita a partir de uma posição fixa no terreno. Os sistemas dinâmicos podem ser os sistemas utilizados acoplados a uma plataforma em movimento. $\mathrm{Na}$

Figura 1), há exemplo dos diferentes tipos de sistemas dinâmicos.
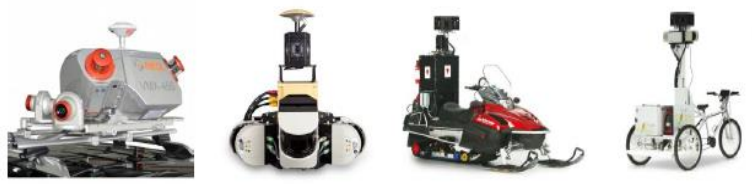

Figura 1- Diferentes tipos de sistemas dinâmicos. Fonte: Chow (2014).

Os sistemas estáticos podem ser classificados em três grupos, de acordo com o seu princípio de funcionamento, sendo eles: tempo de voo do sinal, diferença de fase e triangulação (WUTKE, 2006). Porém Chow (2014) dá a mesma classificação de Wutke (2006), mas à denomina como sendo a partir do princípio de medição de distâncias.

As coordenadas $(\mathrm{X}, \mathrm{Y}, \mathrm{Z})$ dos pontos sobre o objeto estão referenciadas ao centro de fase do equipamento, cuja definição é dada pela interseção do eixo principal e do seu eixo secundário.

Estas coordenadas são função dos parâmetros medidos conforme as Equações (1) a (3) (MEDINA, 2012):

$$
\begin{aligned}
& X=D I \cdot \cos (V) \cdot \operatorname{sen}(H z) \\
& Y=D I \cdot \cos (V) \cdot \cos (H z) \\
& Z=D I \cdot \operatorname{sen}(V)
\end{aligned}
$$

onde:

DI: é a distância inclinada entre o SVLT e o objeto;

$V$ : é o ângulo vertical;

$H z$ : é o ângulo horizontal.

No princípio baseado na triangulação (Figura 2), um pulso de laser é emitido pelo sistema em direção ao objeto de interesse e é refletido em direção a uma ou mais câmaras de digitais, que fazem o registro do sinal. Os ângulos de varredura dos pulsos são registrados no sistema a cada emissão e conhecendo-se a base fixa entre o sensor e a câmara, por meio de um processo de calibração, determinase a posição dos pontos refletidos pelo objeto (DALMOLIN, 2004).

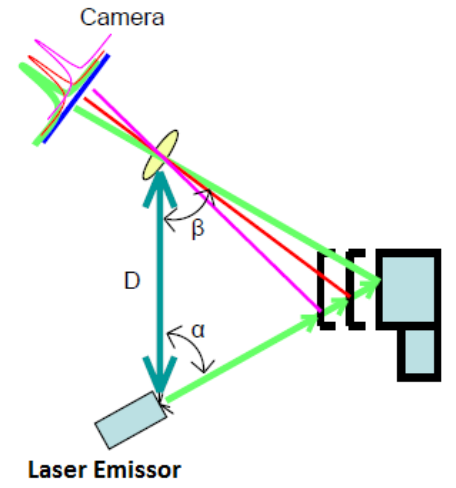

Figura 2 - Princípio da Triangulação. Fonte: Lerma Garcia et al. (2008).

O sensor que captura o pulso laser transforma a luz refletida em sinais elétricos e estes são convertidos em bits através de um conversor analógico digital. A precisão da reconstrução do modelo do objeto depende de elementos geométricos semelhantes, como a relação base/ distância (TOMMASELLI, 2003). Logo, com esta tecnologia, pode alcançar uma precisão de alguns micrômetros.

Os SVLT que funcionam com o princípio do tempo de voo de sinal são equipamentos com medidores de distâncias, que normalmente empregam componentes, tais como, um transmissor laser, um receptor, um relógio para medir o tempo e um transmissor e receptor óptico. Segundo Schofield e Breach (2007), no princípio de tempo de voo (Figura 3), um curto e intenso pulso de radiação é emitido pelo transmissor ao alvo, que reflete um sinal paralelo até o receptor. Assim, a distância é calculada pelo tempo decorrido entre a emissão e a recepção do sinal, o qual é multiplicado pela velocidade da luz.

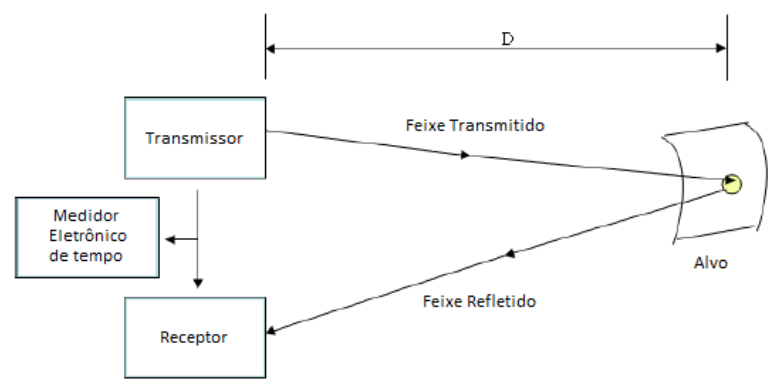

Figura 3 - Princípio do tempo de vôo de sinal. Fonte: Lerma Garcia et al. (2008).

Segundo Tommaselli (2003), o instrumento registra o tempo, a intensidade da energia refletida pelo objeto escaneado, e os parâmetros de atitude do feixe, que são coordenadas polares do ponto em relação ao centro de fase do laser. Com estes dados é possível calcular a distância e as coordenadas cartesianas tridimensionais dos pontos medidos em relação ao centro de fase do sensor.

Já em relação ao princípio da diferença de fase (Figura 4), Medina (2012) define os sistemas LST baseados 
naqueles que usam ondas do espectro infravermelho, luz visível ou micro-ondas para a medição da distância.



Figura 4 - Princípio da diferença de fase. Fonte: Lerma Garcia et al. (2008).

A diferença de fase, entre os sinais transmitidos e refletidos, da parte fracionada do comprimento é menor que o valor da parte inteira do comprimento da onda modulada. Seu intervalo de medição de distâncias é restrito ao máximo de 100 metros com precisão de medidas de distância de alguns milímetros (FRÖHLICH e METTENLEITER, 2004).

Na Figura 5, há exemplos dos diferentes tipos de SVLT em função do método de obtenção de distâncias ou princípio de funcionamento.

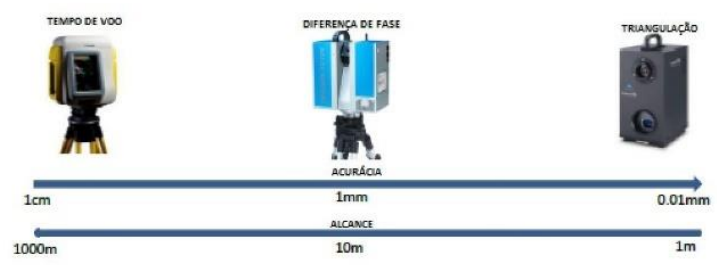

Figura 5 - Diferentes tipos de LST. Fonte: Chow (2014).

\section{ALGUMAS APLICAÇÕES DE SISTEMAS DE VARREDURA A LASER}

Há diversas marcas de equipamentos no mercado e, dentre as marcas mais conhecidas, pode-se citar as das empresas Optech, Leica, Riegel, etc (Figura 6).
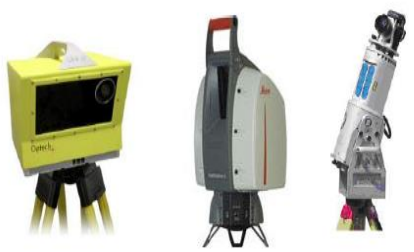

Figura 6 - Diversas marcas comerciais de LST. Fonte: Lerma Garcia et al. (2008).

Mais detalhes sobre as características técnicas de cada tipo de aparelho podem ser encontrados em Wutke (2006) e Gonçales (2007).

Um exemplo de aplicação é apresentado por Meouche et al (2013), que utilizaram um LST para gerar uma modelagem numérica de terreno com a finalidade de determinar zonas de risco de inundação em áreas urbanas. Guarnieri et al (2009) fizeram uma abordagem de utilização de filtros para a geração de modelos digitais de terreno em uma região de pântano em Veneza na Itália. Outro exemplo pode ser encontrado em Schulz (2007), que estudou aspectos referentes à calibração e avaliação da qualidade das medições de distância e ângulo, e os parâmetros que influenciam essas medições e etapas que envolveram o pós-processamento de nuvens de pontos.

Pirotti et al (2013) fizeram uma análise que aborda estudos referentes ao estado da arte nas pesquisas que utilizaram SVLT em relação a resolução de nuvens de pontos, precisão e acurácia de medidas obtidas com a utilização desse tipo de sensores. Pfeifer e Briese (2007) abordaram a aquisição e processamento de dados utilizando plataformas aéreas e terrestres. Gonçales (2007) fez estudos com aplicação na engenharia civil, utilizando um LST voltado à construção de túneis.

A utilização de tecnologia LIDAR, nesse caso utilizando uma plataforma aerotransportada, também possui aplicações em função do comprimento de onda do sensor. A maioria dos sistemas que utilizam a tecnologia LIDAR que são utilizadas com aplicações topográficas empregam a luz laser na faixa espectral infravermelho (IR), médio ou próximo, na região entre 900 e $1500 \mathrm{~nm}$.

Também existem sensores que utilizam a luz azulverde centrada aproximadamente em $532 \mathrm{~nm}$, que são usados em mapeamentos batimétricos devido a sua capacidade de penetração na água (MIKHAIL et al, 2001). A medição da profundidade é feita utilizando dois feixes de REM (radiação eletromagnética), um na faixa do infravermelho e outro na faixa do visível (azul-verde) (Figura 7).

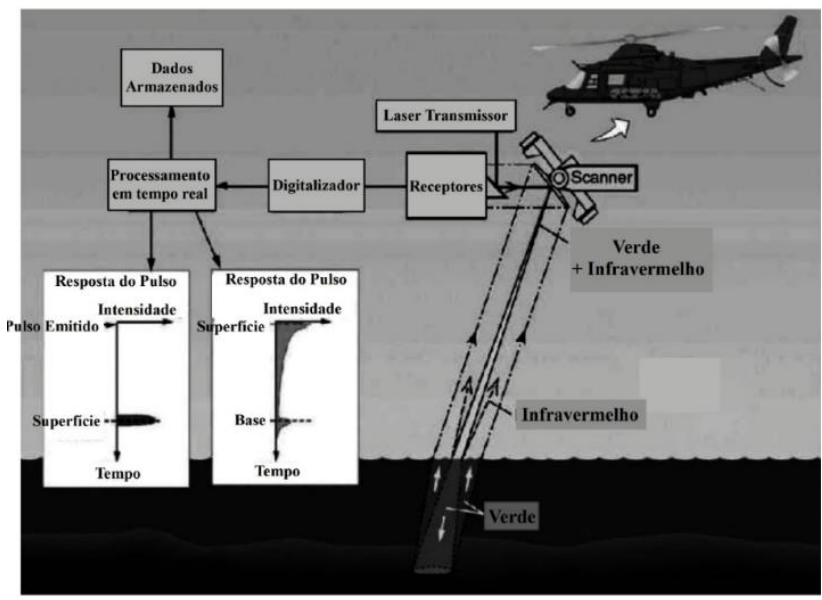

Figura 7 - Medições batimétricas utilizando tecnologia LIDAR. Fonte: Shan e Toth (2009).

A radiação infravermelha é refletida a partir da superfície da água (Figura 7), enquanto que a luz visível (verde-azul) penetra na água e é refletido pelo fundo do mar, que retorna ao sensor. A profundidade real que pode ser medida está limitada a 25-70 m, dependendo do sistema que está sendo utilizado e as características físicas da água (limpidez, velocidade da água, algas, etc.) através do qual a radiação penetra (SHAN e TOTH , 2009). 


\section{INTENSIDADE DE RETORNO DO SINAL}

Os dados brutos de uma varredura LST fornecem as coordenadas tridimensionais de uma nuvem de pontos, os valores de intensidade do retorno do sinal, os dados RGB por meio das fotografias adquiridas por câmaras fotográficas integradas, mais os valores das normais (vetores normalizados) das coordenadas X, Y e Z (

Figura 8).

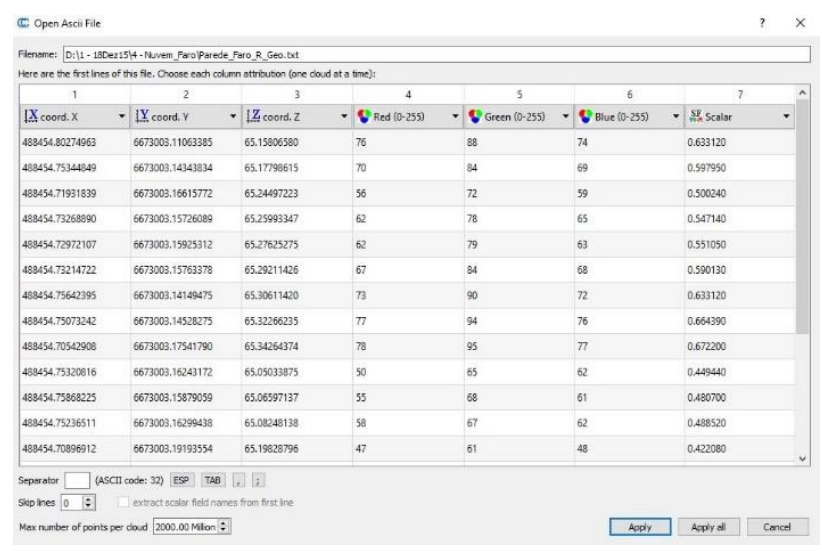

Figura 8 - Dados brutos de um SVLT. Fonte: Elaborado pelo autor.

Jensen (2011) afirma que a intensidade de retorno do sinal representa os picos de voltagens dos sinais de retorno registrados pelo controlador do LST, ou seja, a intensidade representa o número de fótons e a energia que retornam para o receptor e que a intensidade é uma função do material que constitui a superfície escaneada. Com essa informação o LST é capaz de detectar eflorescências, umidade, biodeterioração e realizar a detecção de fissuras em estruturas.

A característica de geração de nuvens de pontos tridimensionais da superfície escaneada com dados de intensidade e cor pode possibilitar o armazenamento de informações de uma inspeção para acompanhamento de evolução de manifestações patológicas ao longo da vida útil de uma estrutura.

A intensidade do feixe de laser refletido tem importância uma vez que a amplitude do sinal recebido está correlacionado com a qualidade de alcance do sinal emitido pelo sensor. A intensidade (I) é influenciada por três parâmetros (SCHULZ, 2007):

- A distância do objeto ( I 1/d $\mathrm{d}^{2}$ );

- A reflectância do objeto;

- O ângulo de incidência.

A Figura 9, apresenta a intensidade de um alvo com uma reflectância de $90 \%$ e mostra que a intensidade diminui também sistematicamente. Por exemplo, a linha de intensidade do alvo com uma reflectância de $20 \%$ corresponde à linha de intensidade para um alvo com uma reflectância de $90 \%$ e um ângulo de incidência de $30^{\circ}$. Na Figura 10, demonstra os valores de intensidade em função do ângulo de incidência do alvo escaneado.

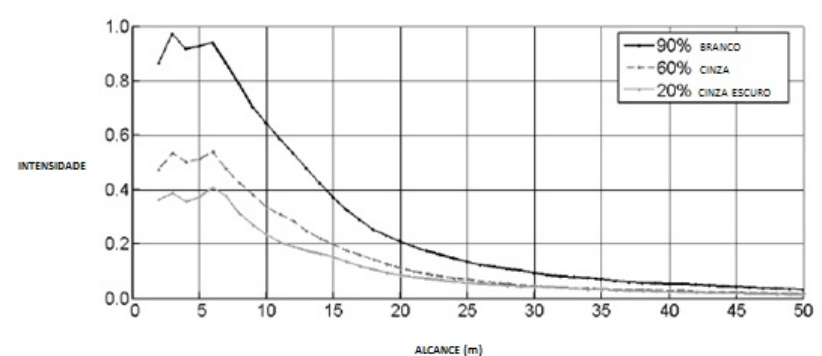

Figura 9 - Valores de intensidade de retorno do sinal em função da refletância de determinados alvos.

Fonte: Schulz (2007).

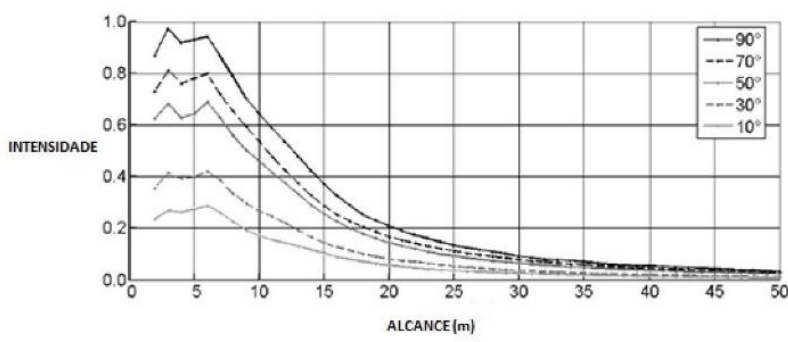

Figura 10 - Valores de intensidade de retorno do sinal em função do ângulo de incidência.

Fonte: Schulz (2007).

Os valores da intensidade apresenta-se menores em relação aos baixos valores de reflectância e baixos ângulos de incidência. Na Figura 11, há um exemplo da utilização de uma imagem e intensidade de uma parede localizada no Departamento de Geociências da Universidade Federal do Rio Grande do Sul (UFRGS).

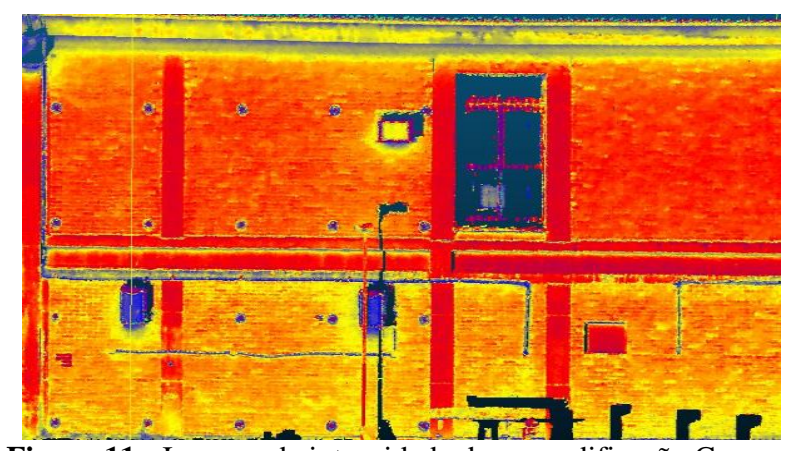

Figura 11 - Imagem de intensidade de uma edificação Campus do Vale da UFRGS.

Fonte: Elaborado pelo autor.

Os dados obtidos através de varreduras laser podem gerar dois tipos de abordagens. Uma geométrica, onde são realizadas analises a partir das coordenadas tridimensionais, obtidas durante a varredura com controle de qualidade na geração de mapas topográficos, registro de monumentos históricos, cálculos de volumes e etc. A outra abordagem que pode ser analisada é em relação ao comportamento físico oriundo da informação espectral fornecida pelo SVLT, já que o sensor opera na faixa do infravermelho (médio ou próximo). Essa análise pode ser obtida em relação ao comportamento físico, que pode ser obtida a partir da imagem de intensidade. 
Godycka et al (2014) realizaram uma experiência com uma viga de concreto sofrendo diferentes tensões a partir de uma prensa hidráulica (Figura 12).
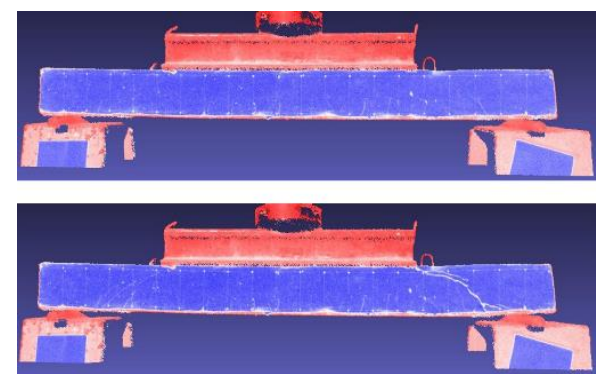

Figura 12 - Análise de deformação em estruturas usando imagem de intensidade gerada por um SVLT.

Fonte: Godycka et al (2014).

Foram aplicadas diferentes tensões na viga e foram realizados escaneamentos durante a aplicação da força. Depois foi realizada uma análise do comportamento da estrutura a partir da imagem de intensidade.

\section{RETORNOS LIDAR}

Durante o escaneamento um pulso de energia é enviado diretamento em direção ao alvo com um determinado ângulo em relação ao espelho do LST. Dependendo da posição do instrumento cada pulso irá iluminar no alvo uma área com um formato de um círculo, denominada de área de cobertura laser instantânea. Esse pulso pode gerar um retorno ou múltiplos retornos (JENSEN, 2011).

Assim toda e energia emitida pelo sensor interage com a superfície do terreno e seria assumido que essa interação resultasse num único retorno. Entretando as diferentes feições que compõem o terreno irão gerar diferentes retornos em função da forma e dimensão do alvo que receberá a energia incidente. Desta forma, cada pulso transmitido da fonte emissora pode gerar múltiplos retornos (Figura 13).

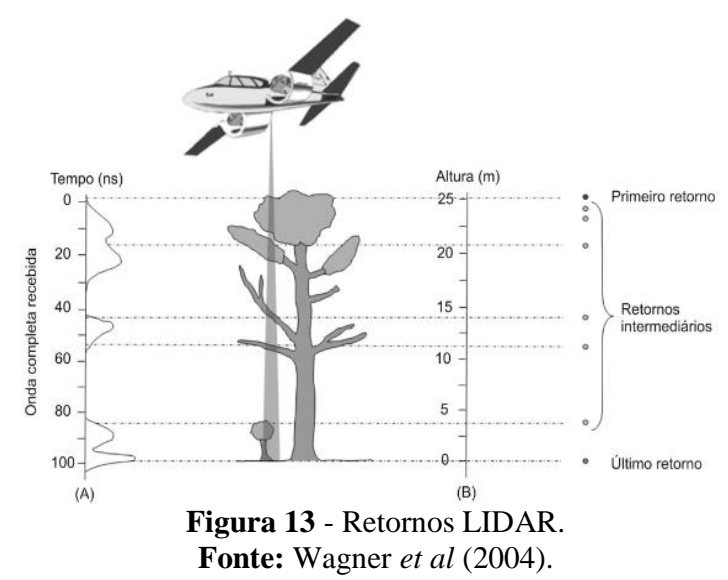

Esses retornos podem ser manipulados e separados. As informações referentes aos primeiros retornos serão direcionadas para a geração de Modelos Digitais de Superfície (MDS), últimos retornos para Modelos Digitais de Terreno (MDT) e de todos os retornos para Modelos Digitais de Elevação (MDE).

\section{CONDIÇÕES AMBIENTAIS PARA USO DE UM LST.}

A temperatura no interior do scanner pode ser muito superior a da atmosfera circundante devido ao aquecimento do ambiente ou aquecimento interno resultante da radiação externa, ou seja, o Sol. Esta fonte de radiação externa pode aquecer um lado do tripé ou o escaner, distorcendo lentamente os dados do SVLT. Não só a temperatura do equipamento, mas a temperatura da superfície a ser escaneada é de importância fundamental. Ao escanear um alvo quente, por exemplo, num ambiente industrial, a radiação de fundo causado pela superfície quente reduz a relação entre o alvo e o feixe de radiação eletromagnética e, assim, a precisão das medições de distância (LERMA GARCIA, 2008).

Os SVLT só irão funcionar corretamente quando utilizado num determinado intervalo de temperatura. Mesmo dentro de distâncas curtas pode-se observar desvios em medições. Como em todas as operações de medição à distância baseados em laser, erros naturais decorrem, principalmente de variações atmosféricas de temperatura, pressão e umidade, que afetam o índice de refração, e modificam o comprimento de onda de energia eletromagnética. Isto significa, que a velocidade da luz laser é fortemente dependente da densidade do ar.

A maioria dos softwares de aquisição de varredura a laser prevê e corrige essa refração, definindo um parâmetro para ela. Em geral, os SVLT são predefinidos usando o parâmetro de atmosfera padrão ISO $\left(15^{\circ} \mathrm{C}, 1013,25 \mathrm{hPa}\right)$. Ao trabalhar sob diferentes condições atmosféricas, diferentes da atmosfera padrão, estes parâmetros devem ser adaptados. Uma diferença de temperatura de $10^{\circ} \mathrm{C}$ ou na pressão de ar de $35 \mathrm{hPa}$ leva a um erro de distância de 1 milímetro / 100m (LERMA GARCIA, 2008).

Uma vez que o sensor opera numa banda de frequências muito estreita, a precisão da medição do intervalo pode ser influenciada também por radiação externa, por exemplo a partir de fontes de forte iluminação exterior. Filtros de interferência óptica especiais podem ser aplicados na unidade receptora, permitindo apenas as frequências corretas para alcançar o receptor.

\section{DIÂMETRO DE VARREDURA GERADOS POR PULSOS EM FUNÇÃO DA DISTÂNCIA DE ESCANEAMENTO}

Quando é efetuado o escaneamento a partir de um SVLT, cada pulso ao atingir um alvo projeta nele um círculo que pode ter um determinado diâmetro d'( Figura 14). 


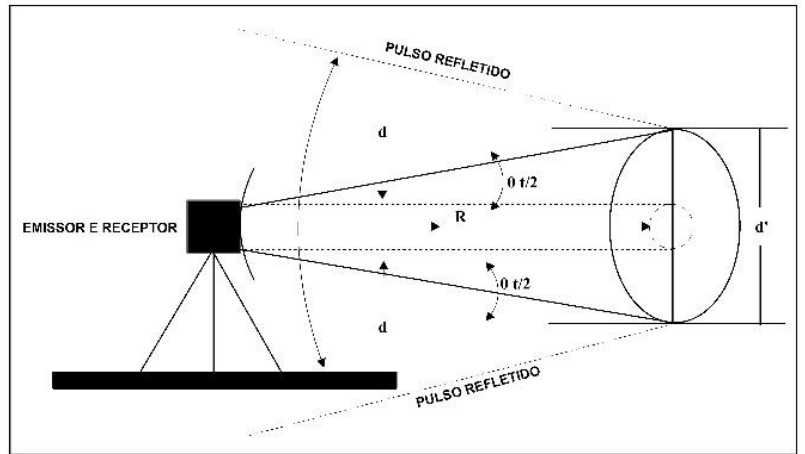

Figura 14 - Diâmetro do círculo projetado por um pulso emitido pelo SVLT.

Fonte: Adaptado de Shan e Toch (2009).

Esse diâmetro e influenciado diretamente pela divergência do pulso emitido pelo SVL. O retorno do sinal é função da dispersão da energia do pulso laser dentro da área formada pela projeção do ponto no alvo (BRANDALIZE, 2001).

Na Tabela 1, há as especificações de um LST fabricado pela empresa Optech, modelo Ilris 3D Hd.

\begin{tabular}{l|l}
\hline Acurácia de Alcance & $\begin{array}{l}4 \text { a 7mm para 100 } \\
\text { metros }\end{array}$ \\
\hline Acurácia angular & $8 \mathrm{~mm}$ para 100 metros \\
\hline \multirow{2}{*}{ Alcance máximo } & $\begin{array}{l}400 \text { metros, para objetos } \\
\text { com refletividade de } \\
10 \%\end{array}$ \\
\cline { 2 - 2 } & $\begin{array}{l}1250 \text { metros, para } \\
\text { objetos com 80\% de } \\
\text { refletividade }\end{array}$ \\
\hline Campo de Visão & \multicolumn{1}{|c}{$40^{\circ}$ x 40 $10 \mathrm{Khz}$} \\
\hline Frequência & \multicolumn{1}{|c}{$1535 \mathrm{~nm}$} \\
\hline $\begin{array}{l}\text { Comprimento de onda } \\
\text { do laser }(\lambda)\end{array}$ & $\begin{array}{l}\text { Classe } 1 \text { (inofensivo aos } \\
\text { olhos) }\end{array}$ \\
\hline Classe Laser & \multicolumn{1}{|c}{$0.008594^{\circ}(150 \mu \mathrm{rad})$} \\
\hline $\begin{array}{l}\text { Divergência do feixe } \\
\text { laser }\end{array}$ & \\
\hline
\end{tabular}

Tabela 1 - Características do SVLT Optech Ilris 3D HD. Fonte: Teledyne Optech (2016).

Quanto maior esse círculo maior será a dispersão do valor da coordenada do ponto medido. Baltsavias (1999), descreve a fórmula da Equação 4, para calcular o diâmetro de um círculo, para um Sistema de Varredura Aerotransportado (SVAT) projetado, a partir do ângulo de varredura, distância do alvo e divergência do feixe laser.

$$
d^{\prime}=\frac{R}{\cos ^{2}(\theta)} \cdot(\gamma)
$$

Onde:

d' = Diâmetro do círculo projetado.

$\mathrm{h}=$ Distância entre o SVLT e o alvo. $\gamma=$ Divergência do feixe laser.

$\theta=$ Angulo de abertura do sensor.

Usando a Equação 4 e os dados referente a Tabela $1\left(\theta=40^{\circ}, \mathrm{h}=15 \mathrm{~m}, \gamma=150 \mu \mathrm{m}\right)$ para uma distância de 15 (quinze) metros o valor do diâmetro do círculo projetado ficará em 3.8 milímetros.

Para distâncias de 400 e 1200 metros, que são valores de distâncias medidas pelo LST Optech com refletividade de $10 \%$ e $80 \%$ esses valores ficam em 10.2 $\mathrm{cm}$ e $30.6 \mathrm{~cm}$ respectivamente.

\section{UTILIZAÇÃO DE FILTROS E COMPARAÇÃO COM A FOTOGRAMETRIA NA GERAÇÃO DE MDT}

Existem diversas maneiras de se obter um modelo digital de terreno. Pode se adquirir um MDT por interpolação de pontos obtidos por estação total ou com rastreio GNSS, por interpolação de curvas de nível ou pontos cotados extraídos de cartas topográficas, através de Radar, Fotogrametria e também através de nuvens de pontos oriundas de tecnologia LIDAR (terrestre ou aerotransportada). Todos os métodos possuem vantagens e desvantagens, porém aqueles que conseguem informações tridimensionais do terreno de maneira mais abrangente (maior área) e mais rápida são a Fotogrametria, Radar e LIDAR.

Habbib (2007) compara os métodos de aquisição de pontos tridimensionais por laser e Fotogrametria e cita vantagens e desvantagens dos dois métodos. Uma das vantagens da tecnologia LIDAR é que a obtenção de coordenadas é realizada de maneira direta enquanto que na Fotogrametria a obtenção de coordenadas é obtida de maneira indireta. Já, uma das vantagens da Fotogrametria, principalmente a terrestre é que ela é bem mais barata comparada com o escaneamento laser. Habbib (2007) também descreve que a acurácia vertical da tecnologia $L I D A R$ é melhor que a obtida por Fotogrametria, porém a acurácia horizontal da Fotogrametria é melhor.

O método de varredura a laser é bastante efetivo na tarefa de aquisição de MDT. Em Fotogrametria esta mesma tarefa pode ser realizada com níveis parecidos de automação, mas o método de varredura a laser possui vantagens em relação aos métodos fotogramétricos convencionais de geração de MDT. Uma vantagem notável e a capacidade (de parte dos pulsos laser) de penetrar áreas de vegetação e atingir o terreno, permitindo a eliminação da vegetação de maneira rápida e eficaz. Os métodos de eliminação de vegetação e outras feições existentes no terreno, de forma a deixar somente pontos laser pertencentes ao terreno, são conhecidos como de filtragem (DAL POZ, 2013).

Sithole (2001) apresentou um filtro que utiliza a declividade como parâmetro para diferenciar os pontos que fazem parte do MDT daqueles que fazem parte do MDS.

Pirotti et al (2012) também realizaram estudos utilizando filtros morfológicos de classificação de vegetação utilizando um LST Riegl VZ-400. Uma visão geral dos métodos de filtragem em nuvens de pontos 
utilizando plataformas aerotransportadas é apresentado em Vosselman e Maas (2010) e são divididas em três grupos: um baseado em morfologia matemática, um de densificação progressiva de uma malha de triângulos, e outro baseado em interpolação linear hierárquica.

\section{AQUISIÇÃO DE MDT A PARTIR DE DADOS LIDAR}

Conforme Andrade (1998), modelar um terreno significa reproduzir a sua forma. Quando esta reprodução é realizada por meios digitais, diz-se que se fez um modelo digital de terreno (MDT). Existem muitas formas de modelar a superfície de um terreno. No processo de interpolação de altitudes é que fica definida a forma de representação da superfície que se pretende modelar.

Para Jensen (2011) modelos digitais de terreno são aqueles que contêm informação de elevação da superfície desnuda da Terra, sem influência de vegetação ou de feições construídas pelo homem como postes, prédios, casas etc.

A obtenção de um MDT a partir de dados LIDAR, seja através de uma plataforma aérea ou terrestre, requer a identificação de pontos que correspondem a feições existentes no terreno, para que em gabinete esses dados possam ser manipulados. Lohmann et al (2000) designa o termo "filtragem" ao processo de identificação de pontos no terreno e pontos elevados acima dele, enquanto o termo "classificação" é adotado por Briese e Pfeifer (2001). Em virtude da eliminação dos pontos acima do terreno, ocorre uma significativa redução dos dados obtidos, cujas lacunas são preenchidas por processos de interpolação (SHIMALESKY, 2007). Segundo Sithole e Vosselman (2005), pode-se ainda gerar o modelo digital do terreno numa área coberta por vegetação, identificando do conjunto de dados, os pontos mais baixos que são os pulsos que atingiram o terreno (últimos retornos), e filtrando o restante dos pulsos.

Para Sithole e Vosselman (2005), os métodos de filtragens assumem diferentes abordagens a respeito da estrutura do terreno no local, o que condiciona a seleção da metodologia adotada pelo filtro afetando seu desempenho.

\section{ACURÁCIA DOS DADOS GERADOS}

O trabalho de mensuração envolve diversas etapas. Desde os trabalhos de planejamento em gabinete, levantamentos de campo e a finalização e geração do produto final em escritório. Qualquer atividade que envolva a obtenção de medidas sempre existe algum tipo de erro associado. Esses tipos de erros podem ser classificados em: grosseiros, sistemáticos e aleatórios.

Os erros grosseiros podem ser oriundos da falta de experiência ou por desatenção de quem realiza o processo de medição. Os erros sistemáticos podem indicar algum problema no instrumento de medição e os erros aleatórios ou acidentais são aqueles que ocorrem de maneira fortuita, ao acaso.

Como existem diversas fontes e tipos de erros, notase que a grandeza denominada de valor verdadeiro nunca é conhecida. Assim, para cada tipo de mensuração adota-se um valor como referência. Assim, para se estimar a qualidade de qualquer dado que foi medido, compara-se ele com o seu valor de referência. Porém, para tentar minimizar a existência de erros, faz-se necessário uma determinada quantidade de medições para que exista redundância e assim possa-se determinar uma solução única para o problema em questão.

O ideal de cada processo de medição seria a inexistência de erros. A inexistência de erros recebe o nome de exatidão. Ou seja, a exatidão é considerada um processo sem qualquer tipo de erro. A acurácia representa a proximidade de uma medida em relação a um valor adotado como verdadeiro. $\mathrm{O}$ termo precisão demonstra o grau de consistência de uma medida em relação a sua média.

Assim, nota-se que o termo exatidão se refere a um processo de medição considerado ideal com ausência total de erros, algo impossível de acontecer. O termo acurácia envolve apenas erros aleatórios, ou seja, que ocorrem ao acaso que fica regulado pela lei das probabilidades. $\mathrm{O}$ termo precisão engloba tanto efeitos aleatórios como sistemáticos, ou seja, além de falhas ocasionais no processo de medição também está sujeito a falhas instrumentais.

Como todo processo de medição é passível de erros o ideal é a sua minimização. Para a eliminação de erros grosseiros pode-se adotar um maior rigor no momento da medição.

No Brasil, não existe uma definição clara e objetiva quanto aos métodos para a determinação de controle de qualidade posicional de dados cartográficos. A legislação classifica os produtos cartográficos em função do padrão de exatidão cartográfica (PEC) que é normatizado pelo Decreto-Lei 89.817.

Diversos autores como Mikhail e Ackermann (1976), Galo e Camargo (1994), Rocha (2002) e Santos (2010) realizaram trabalhos que abordaram temas envolvendo controle de qualidade posicional de produtos cartográficos. Nesses trabalhos conceitos de acurácia, exatidão, precisão e estatística espacial são analisados.

Para a determinação da acurácia de um modelo digital de terreno ou de superfície, normalmente determinam-se pontos de controle com coordenadas tridimensionais espalhados ao longo da área de estudo, usando uma técnica de alta precisão de levantamentos.

Pode-se combinar dados de levantamento GNSS (Global Navigation Satellite System) com estação total e a partir desses dados verificar as discrepâncias dos valores das coordenadas comparadas. Para Miller (2004) o padrão de acurácia geoespacial para dados planimétricos e altimétricos definidos pelo FGDC (Federal Geographic Data Comitee) é baseado no cálculo do Erro Médio Quadrático (EMQ)

$$
E M Q=\sqrt{\frac{\sum_{i=1}^{n} \Delta^{2}}{n}}
$$


Onde $\Delta$ é a diferença entre a medida do ponto de verificação obtida no terreno e a medida obtida pelo LST no mesmo local. O padrão recomenda que seja usado um mínimo de 20 pontos de controle e os mesmos devem ter uma acurácia substancialmente maior do que os produtos obtidos pelo LST (MILLER, 2004).

A acurácia planimétrica (AP) (Equação 6) com um nível de confiança de $95 \%$ é calculada usando a seguinte fórmula:

$$
A P=2.447 \cdot \frac{(E M Q x+E M Q y)}{2}
$$

A acurácia vertical (AV) (Equação 7) com um nível de confiança de $95 \%$ é calculada usando a seguinte fórmula:

$$
A V=1.96 \cdot E M Q z
$$

Miller (2004) descreve que as acurácias verticais de dados laser obtidos através de varreduras aerotransportadas variam normalmente entre 05 e $30 \mathrm{~cm}$.

Porém, esses dados são afetados por elementos como a influência da cobertura do solo, declividade, presença ou ausência de folhagens nas vegetações existentes no terreno e posição do sensor.

Mikhail e Ackerman (1976), definem acurácia como o grau de proximidade de uma estimativa com seu parâmetro ou valor utilizado como verdadeiro. Outrossim, os autores definem o termo precisão como grau de inconsistência da grandeza medida com a sua média.

Também outro método de se avaliar a acurácia ou precisão posicional é a partir de dois testes estatísticos que verificam se existe tendência nas componentes (coordenadas $\mathrm{E}, \mathrm{N}$ e h) analisadas.

Primeiramente são feitas duas formulações que irão embasar um teste de hipótese:

$\mathrm{H} 0=0$, consiste na primeira hipótese, define que os dados da amostra analisada estão dentro de um intervalo de confiança analisado, assim definido como hipótese básica.

H0>0, denominada de hipótese alternativa, informa que os dados da amostra analisada estão fora do intervalo de confiança determinado, assim a hipótese básica é rejeitada.

Depois são realizados dois testes, baseado na média (Equação 8), desvio-padrão (Equação 9) e variância das discrepâncias dos dados analisados.

O primeiro teste, denominado de teste de tendência, ou teste T (Santos, 2010) analisa se existe tendência nas componentes analisadas. $\mathrm{O}$ teste $\mathrm{T}$, utiliza como parâmetros a média (Equação 8), desvio-padrão (Equação 9) e os graus de liberdade (gl) da amostra.

Assim, utilizando a Equação 10 é definido um valor, no caso, Tcalc. Esse valor é comparado com a tabela $T$ Student, a partir no intervalo de confiança e dos graus de liberdade da amostra analisada.

Caso o valor encontrado na Equação 10, seja, menor que o valor teórico, o encontrado na tabela $T$ Student, a hipótese nula é aceita. Caso o valor calculado seja maior que o teórico a hipótese nula é rejeitada e a hipótese alternativa é aceita indicando que existe tendência na amostra.

$$
\begin{aligned}
& \overline{\Delta x}=\frac{1}{n} \sum_{i=1}^{n} \Delta x_{i} \\
& \sigma_{\overline{\Delta x}}=\sqrt{\frac{1}{n-1} \sum_{i=1}^{n}\left(\Delta x_{i}-\overline{\Delta x}\right)^{2}} \\
& \text { Tcalc }=\frac{\overline{\Delta x}}{\sigma \overline{\Delta x}} \cdot \sqrt{g l}
\end{aligned}
$$

O teste de precisão (Santos, 2010) é realizado utilizando como parâmetro a variância da amostra, que nada mais é que a raiz quadrada positiva do desvio-padrão. Nesse teste é utilizada a Tabela $\chi^{2}$ (qui-quadrado).

$$
\chi_{\text {calculado }}^{2}=(g l) \cdot \frac{\sigma_{\frac{2}{\Delta x}}^{2}}{\sigma_{x}^{2}}
$$

$\mathrm{O}$ teste $\mathrm{T}$, nos informa se existe tendência nas components analisadas. Para se determinar o valor da tendência em cada coordenada, pode-se utilizar a Equação 12 (MIKHAIL e ACKERMAN,1976):

$$
E M Q=\sigma p^{2}+(b)^{2}
$$

Onde $\sigma p^{2}$ representa a incerteza ou variância das observações e $b$ representa o vício do estimador (tendência).

Para ratificar os conceitos abordados, segue abaixo uma comparação de controle de qualidade posicional gerado por dois SVLT. Um sistema fabricado pela empresa Optech, modelo Ilris 3D Hd e o outro, fabricado pela empresa Faro, modelo Focus 3D 120S.

Os testes foram realizados em Porto Alegre-RS, no Campus do Vale da Universidade Federal do Rio Grande do Sul (UFRGS).

Foi utilizado uma parede de calibração, Figura 15, onde nela foram medidos 29 pontos, com visadas duplas, com uma estação total da marca Topcon modelo 7500. 


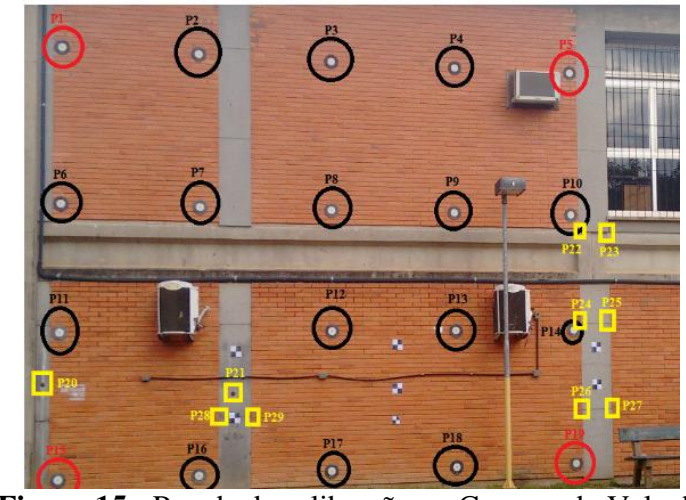

Figura 15 - Parede de calibração no Campus do Vale da UFRGS.

Fonte: Elaborado pelo autor.

Os pontos P1, P5, P15 e P19, foram utilizados para fazer o georreferenciamento das nuvens de pontos gerados pelos dois LST. Os outros pontos, total de 25, serviram de comparação com as coordenadas medidas com estação total.

A acurácia descrita nos manuais dos LST são de $2 \mathrm{~mm}$ (LST Faro) para distâncias de até 25 metros e 4 a 7 mm (LST Optech) para distâncias de até 100 metros.

Analisando os resultados descritos na Tabela 2 e Tabela 3, nota-se que os valores de acurácia estão bem abaixo daquela descrita no manual dos LST.

\begin{tabular}{l|c|c|c}
\hline \multicolumn{4}{c}{ OPTECH ILRIS 3D HD } \\
\hline Discrepâncias (m) & $\mathrm{E}$ & $\mathrm{N}$ & $\begin{array}{c}\mathrm{H} \\
\text { (Ortométrica) }\end{array}$ \\
\hline Média (m) & -0.0056 & 0.0014 & 0.0002 \\
\hline Desvio-Padrão (m) & 0.008 & 0.008 & 0.007 \\
\hline EMQ (m) & 0.0095 & 0.0081 & 0.0067 \\
\hline Máximo (m) & 0.010 & 0.022 & 0.024 \\
\hline Mínimo (m) & -0.023 & -0.019 & -0.014 \\
\hline Amostra & 25 & 25 & 25 \\
\hline G. Liberdade (gl) & 24 & 24 & 24 \\
\hline T Std Teórico & 2.064 & 2.064 & 2.064 \\
\hline T Std Amostral & 3.548 & 0.821 & 0.155 \\
\hline Tendencioso & SIM & NÃO & NÃO \\
\hline$\chi^{2}$ Teórico & 37.652 & 37.652 & 37.652 \\
\hline Acurácia (m) & 0.00004 & 0.00004 & 0.00003 \\
\hline
\end{tabular}

Tabela 2 - Análise de controle de qualidade posicional utilizando um LST da empresa Optech modelo Ilris 3D Hd.

Fonte: Elaborado pelo autor.

\begin{tabular}{l|c|c|c}
\hline \multicolumn{4}{c}{ FARO FOCUS 3D } \\
\hline Discrepâncias (m) & $\mathrm{E}$ & $\mathrm{N}$ & $\begin{array}{c}\mathrm{H} \\
\text { (Ortométrica) }\end{array}$ \\
\hline Média (m) & -0.0007 & 0.0003 & 0.0006 \\
\hline Desvio (m) & 0.006 & 0.008 & 0.008 \\
\hline EMQ (m) & 0.0055 & 0.0077 & 0.0077 \\
\hline Máximo (m) & 0.015 & 0.014 & 0.011 \\
\hline Mínimo (m) & -0.015 & -0.017 & -0.015 \\
\hline Amostra & 25 & 25 & 25 \\
\hline G. Liberdade (gl) & 24 & 24 & 24 \\
\hline T Std Teórico & 2.064 & 2.064 & 2.064 \\
\hline T Std Amostral & 0.540 & 0.186 & 0.370 \\
\hline Tendencioso & NÃO & NÃO & NÃO \\
\hline$\chi^{2}$ Teórico & 37.652 & 37.652 & 37.652 \\
\hline Acurácia (m) & 0.00002 & 0.00004 & 0.00004 \\
\hline
\end{tabular}

Tabela 3 - Análise de controle de qualidade posicional utilizando um LST da empresa Faro modelo Focus 3D. Fonte: Elaborado pelo autor.

A partir da análise dos resultados da Tabela 2 e Tabela 3 , o valor mais coerente para a acurácia posicional dos dois sistemas de varreduras laser, são os resultados a partir do EMQ que variam em cada componente desde $5.5 \mathrm{~mm}$ a 9.5 $\mathrm{mm}$, valores esses compatíveis com os valores de acurácia descritos no manual de operação dos LST.

Efetuando o cálculo da acurácia planimétrica e altimétrica, com intervalo de confiança de 95\%, descrita por Miller (2004) utilizando as Equações 6 e 7, chega-se aos resultados descritos na Tabela 4.

\begin{tabular}{c|c|c}
\hline ACURÁCIA & SVLT FARO & SVLT OPTECH \\
\hline Acurácia Plan. & 0.016 & 0.021 \\
\hline Acurácia Alt. & 0.015 & 0.013 \\
\hline
\end{tabular}

Tabela 4 - Acurácia planimétrica e altimétrica conforme o $F G D C$.

Fonte: Elaborado pelo autor.

\section{DISCUSSÕES E CONCLUSÃO}

A utilização de um LST possui inúmeras aplicações em diversas áreas do conhecimento como engenharias, arquitetura, geologia, arqueologia e estudos ambientais

Modelos de elevação e de terreno, que são produtos que podem ser extraídos das nuvens de pontos possuem muitas aplicações nas áreas das engenharias como em construção de estradas, cálculos de volumes na área de mineração, estudos de bacias hidrográficas, etc. A obtenção de MDT, a partir de um LST, possui uma alta acurácia vertical em comparação com os métodos tradicionais como o Radar, Fotogrametria e também de varreduras laser aerotransportadas.

No presente trabalho foram abordados conceitos voltados para a geração de MDT a partir de nuvens de pontos oriundas de varreduras. Um LST fornece informações físicas (intensidade) e geométricas (coordenadas X, Y e Z) de diversas feições existentes no terreno, que caracterizam os elementos que constituem um 
MDS. Assim para se gerar um MDT pode-se utilizar técnicas de classificação de dados através de diferentes tipos de filtros. Onde, a partir deles pode-se identificar feições tipo postes, árvores, rochas, prédios e eliminá-las das nuvens de pontos. Depois, partir de processos de interpolação, pode-se iniciar a criação do MDT.

Em todo produto cartográfico deve ser realizado um controle de qualidade para se verificar a precisão ou acurácia oriunda de testes estatísticos. A partir dos resultados obtidos pelo controle de qualidade pode-se determinar para quais finalidades o produto pode utilizado.

\section{REFERÊNCIAS BIBLIOGRÁFICAS}

ANDRADE, J. B, Fundamentos de Fotogrametria, 1998, páginas 202 a 204.

BARBER, D., MILLS, J., \& BRYAN, P. (2003). Towards a standard specification for terrestrial laser scanning of cultural heritage. CIPA International Archives for Documentation of Cultural Heritage, 19, 619-624.

BALTSAVIAS, E.P., Airborne Laser Scanning: Basic Relations and Formulas, Institute of Geodesy and Photogrammetry, Switzerland, 1999.

BRANDALIZE, A.A., Perfilamento a Laser: Comparação com Métodos Fotogrametricos, XX congresso Brasileiro de Cartografia, Rio Grande do Sul, Brasil, 2001.

BRASIL. DECRETO LEI n ${ }^{\circ} 89.917$ de 20 de junho de 1984.

BRIESE, C., PFEIFER, N. Airborne LASER Scanning and Derivation of Digital Terrain Models. In Grün/Kahmen (Eds.): Optical 3-D Measurement Techniques. Institut für Photogrammetrie und Fernerkundung - I.P.F. Vienna, 2001.

CHOW, J.C.K. Multi-Sensor Integration for Indoor 3D Reconstruction. Department of Geomatics Engineering. University Of Calgary - CAN. 2014.

DAL POZ, A.P. Filtragem de dados de varredura laser: Princípios e exemplos. Anais XVI Simpósio Brasileiro de Sensoriamento Remoto - SBSR, Foz do Iguaçu, PR. 2013.

DALMOLIN, Q., SANTOS, D. R. Sistema Laser Scanner: conceitos e princípios de funcionamento. Curitiba, UFPR, 2004.

FRÖHLICH, C., METTENLEITER, M..Terrestrial laser scanning - new perspectives in 3D surveying. International Archives of Photogrammetry, Remote Sensing and Spatial Information Sciences, Freiburg, v. 36, n. 8/W2,p. $7-13$, oct. 2004.
GALO, M.; CAMARGO, P. de O. O uso do GPS no controle de qualidade de cartas. In: $1^{\circ}$ Congresso Brasileiro de Cadastro Técnico Multifinalitário. Tomo II, p. 41-48, Florianópolis - Brasil. 1994.

GODYCKA K. N., SZULWIC, J., ZIÓŁKOWSKI, P.The Method Of Analysis Of Damage Reinforced Concrete Beams Using Terrestrial Laser Scanning. Faculty of Civil and Environmental Engineering, Gdansk University of Technology, Poland. 14th International Multidisciplinary Scientific GeoConference SGEM 2014.

GONÇALES, R., Dispositivo de varredura laser 3D terrestre e suas aplicações na Engenharia, com ênfase em túneis, Dissertação de Mestrado da Escola politécnica de São Paulo, São Paulo, São Paulo; 2007.

GUARNIERIA, A., VETTOREA, A., PIROTTIA, F., \& MARANIB, M. Filtering of TLS point clouds for the generation of DTM in salt-marsh areas; 2009.

HABIB A., KERSTING A. P., Ruifanga, Z. , ALDURGHAM, KIM, M. C, LEE, D. C. 2007. Lidar Strip Adjustment Using Conjugate Linear Features in Overlapping Stripts. The International Archives of the Photogrammetry, Remote Sensing and Spatial Information Sciences. Vol. XXXVII. Part B1. Beijing 2007 . pp. 386-390.

JENSEN, J. R. Sensoriamento Remoto do Ambiente - Uma Perspectiva em Recursos Terrestres. Editora Parêntese, 2011.

LERMA GARCÍA, J.L., VAN GENECHTEN, B., HEINE, E., SANTANA QUINTERO, M., Theory and Practice on Terrestrial Laser Scanning. Training Material Based on Practical Applications ISBN: 978-84-8363-379-3. 2 DVDs. 2008.

LOHMANN, P., KOCH, A.; SCHAEFFER, M. Approaches to the filtering of LASER scanner data. The International Archives of Photogrammetry and Remote Sensing, Amsterdam, 2000.

MEDINA, A.S., Uma Proposta De Metodologia para A Extração Semi-automática De Formas Arquitetônicas Planas Utilizando Dados Provenientes De Laser Escaner Terrestre, Tese Doutorado, 2012.

MIKHAIL, E. M., BETHEL, J. S., MCGLONE, J.C. Introduction to Modern Photogrametry. 2001.

MIKHAIL, E.; ACKERMAN, F. Observations and Least Squares. University Press of America, 1976. 497 p.

MILLER, S. B., Photogrametric Products in Manual of Photogrametry, 5th Ed, Bethesda: ASPRS. 2004. 
MEOUCHE, R. E., REZOUG, M., W. VANDEVENNE, W. HAMZAOUI, R. Using a Laser Scanning to Construct a 3D Numerical Model to Study the Flooding Risk in Urban Area. IACSIT International Journal of Engineering and Technology, Vol. 5, No. 3, June 2013.

PIROTTI, F. GUARNIERI, A. VETTORE A. Ground filtering and vegetation mapping using multi-return terrestrial laser scanning. ISPRS Journal of Photogrammetry and Remote Sensing. 2012.

PIROTTI, F. GUARNIERI, A. VETTORE A. State of the Art of Ground and Aerial Laser Scanning Technologies for High-Resolution Topography of the Earth Surface. European Journal of Remote Sensing. 2013.

PFEIFER N.,BRIESE, C. Geometrical Aspects Of Airborne Laser Scanning And Terrestrial Laser Scanning. Iaprs Volume XXXVI, Part 3 / W52, 2007.

PFEIFER, N. Theory and Application of Laser Scanning. International Symposium of Photogrammetry Remote Sensing. ISPRS. Summer School. Ljubljana, Slovenia, Germany, 2007.

ROCHA, R.S. Exatidão cartográfica para cartas digitais urbanas. Tese de Doutorado. Programa de PósGraduação em Engenharia de Produção. Universidade Federal de Santa Catarina. Florianópolis, SC. 2002.

SANTOS, A. P., Avaliação da Acurácia Posicional de Dados Espaciais com uso de Estatística Espacial. Dissertação de Mestrado. Universidade Federal de Viçosa. 2010.

SHIMALESKY, V. Avaliação da qualidade da informação altimétrica derivada da varredura a LASER em uma região coberta por vegetação: um estudo de caso. Dissertação de Mestrado pelo Programa de PósGraduação em Ciências Geodésicas - Universidade Federal do Paraná. Curitiba - Paraná, 2007.

SCHOFIELD, W., BREACH, M. Engineering Surveying. 6a edição. Butterworth-Heinemann Ltda., 2007.

SCHULZ, T. Calibration of a Terrestrial Laser Scanner for Engineering Geodesy. Technical University of Berlin. 2007.

SITHOLE, G., Filtering of laser altimetry data using a slope adaptive filter. International Archives of the Photogrammetry, Remote Sensing and Spatial Information Sciences. 2001.

SITHOLE, G. E G. VOSSELMAN. Comparison of Filter Algorithms. International Archives of Photogrammetry, Remote Sensing and Spatial Information Sciences, 2005, v. 34 (3/W13), pp. 71-78.

SHAN, J., TOTH, C. K. Topographical Laser Ranging and Scanning Principles and Processing. 2009.
TELEDYNE OPTECH. Disponível em: http://www.teledyneoptech.com/index.php/product/op tech-ilris/. Acesso em: 13 de mar. 2016.

TOMMASELLI A. M. G. Um Estudo sobre as Técnicas de Varredura a Laser e Fotogrametria para Levantamento 3D a Curta Distância. Geodésia online, 2003.

VOSSELMAN, George; MAAS, Hans-Gerd (Ed.). Airborne and terrestrial laser scanning. Whittles Publishing, 2010.

WUTKE, J.D. , Métodos Para Avaliação De Um Sistema Laser Scanner Terrestre, Dissertação de Mestrado,Universidade Federal do Paraná, 2006. 